ANUARIO MUSICAL, N. ${ }^{\circ} 65$

enero-diciembre 2010, 145-170

ISSN: 0211-3538

\title{
RESONANCIAS TRISTANESCAS EN LA ÓPERA ESPAÑOLA: WAGNERISMO EN LAS ÓPERAS DE CONRADO DEL CAMPO.
}

\author{
INFLUENCES FROM 'TRISTAN’ IN SPANISH OPERA: WAGNERISM \\ IN THE OPERAS BY CONRADO DEL CAMPO
}

\author{
Víctor Sánchez Sánchez \\ Universidad Complutense de Madrid
}

\begin{abstract}
Resumen:
La obra musical de Conrado del Campo, a pesar de su importancia e influencia en la música española de la primera mitad del siglo xx, permanece en un injusto olvido, especialmente su amplio legado operístico. Se realiza en este artículo un estudio y análisis de las primeras óperas de Conrado del Campo, destacando en ellas tanto la asimilación del wagnerismo imperante en esos años como su interés por desarrollar los ideales de la ópera española. Para ello se han acudido a las fuentes originales: los manuscritos de las partituras, comentarios de la prensa y opiniones del propio compositor, con especial detenimiento en las óperas El final de Don Álvaro y La tragedia del beso, dramas líricos en los que resulta evidente la resonancia del Tristán wagneriano.
\end{abstract}

Palabras clave:

Ópera; Ópera española; Teatro Real; Wagner; Leitmotiv; Influencias musicales; Conrado del Campo; Duque de Rivas; Divina Comedia.

\begin{abstract}
:
In spite of its importance and impact to Spanish music of the first half of twentieth century, Conrado del Campo's output, and particularly his operas, have unfairly been forgotten. This article examines Conrado del Campo's early operas, which reflect a Wagnerian influence and his interest in the development of Spanish opera. Original sources such as the manuscript scores, newspapers reviews and letters written by the composer himself have been consulted and special attention has been paid to the operas El final de Don Álvaro and La tragedia del beso, music dramas heavily influenced by Wagner's Tristan.
\end{abstract}

Key words: Comedia.

Opera; Spanish Opera; Teatro Real; Wagner; Leitmotiv; Musical Influence; Conrado del Campo; Duque de Rivas; Divina 
El compositor Conrado del Campo $(* 1878 ; \uparrow 1953)$ está considerado como una de las grandes personalidades musicales españolas de la primera mitad del siglo xx, tanto por el interés de su amplia producción musical como por su influencia en las generaciones posteriores a través de su cátedra de composición en el Conservatorio de Madrid. Infatigable trabajador, fue capaz de simultanear la composición con su actividad de intérprete y pedagogo ${ }^{1}$. Sin embargo, al contrario que Manuel de Falla y otros músicos de su generación, Conrado del Campo intentó desarrollar la música española desde dentro del país sin buscar otros horizontes en el extranjero. Su discípulo Julio Gómez, en un emotivo artículo en la revista Harmonía aparecido poco después del fallecimiento de su maestro, destacaba el valor de esta postura:

"Dijo en una ocasión el maestro Vives que en la situación en que se hallaba por entonces nuestra organización musical, el compositor español había de enfrentarse forzosamente con el terrible dilema de encanallarse o sucumbir. Muchos han sido los que se han encanallado, o, si nos parece demasiado fuerte la expresión, los que han renunciado a sus ideales para vivir adaptándose al medio. Falla y Turina resolvieron el dilema apartándose de nuestro ambiente y apoyando sus actividades en la organización internacional de la música, tanto, que puede decirse, sobre todo de Falla, que prácticamente no es un compositor español, ya que sus obras son propiedad comercial de casas extranjeras y propiedad de la que da carácter y avalora una firma editorial.

Conrado del Campo ni se encanalló ni se marchó al extranjero. Trabajó sin descanso, en todos los géneros, llevando a todos ellos la pureza de sus ideales. Siempre que se inicia en nuestro ambiente musical un movimiento renovador, siempre que el grupo de compositores españoles que no se resigna a acomodarse dócilmente al rebajamiento circunstante, inicia una regeneración en cualquiera de los géneros de altura, allí está siempre el maestro, siempre el primero en la pureza del ideal, siempre el primero en la generosidad del esfuerzo; porque una de las características que más honran y enaltecen al maestro es que nunca ha pretendido largos premios para ciertos trabajos, sino que ha llegado siempre al máximo de la entrega, sin tener lo que, por desgracia, es entre nosotros corriente: la desproporción y hasta total ausencia de la recompensa."2.

La obra musical de Conrado del Campo -salvo algunas pocas excepciones- ha permanecido en el olvido, no sólo para el público sino también para intérpretes y estudiosos en la música española ${ }^{3}$. Muchas son las causas de esta situación lamentable, aunque la principal se deba al estado manuscrito de su música, ya que apenas llegó a editar unas pocas obras. A modo de ejemplo, de sus catorce cuartetos tan sólo se han editados dos: $n^{\circ} 5$ Caprichos románticos (1908) y $n^{\circ} 13$ Carlos III (1949), no siendo

1 Un interesante estudio sobre la influencia de Conrado de Campo, analizando tanto documentación como rasgos estilísticos, se puede encontrar en Heine, Christiane: "El magisterio de Conrado del Campo en la generación del 27: el caso de Salvador Bacarisse y Ángel Martín Pompey”, en SuÁrez-Pajares, Javier (ed.): Música española entre dos guerras, 1914-1945. Granada, Archivo Manuel de Falla, 2002, pp. 99-131.

2 GómEz, Julio: "Comentarios del presente y del pasado: Conrado del Campo", en Harmonía, año xxxviII, Madrid, (enerojunio 1953), p. 2.

3 Además de algunas pocas grabaciones antiguas, descatalogadas y de difícil acceso, en la actualidad tan sólo se localizan dos discos con música de Conrado del Campo: uno del cuarteto Brodsky con los nos 5 y 13 (Fundación Autor 97052, Madrid, 1997) y otro de la Orquesta Filarmónica de Gran Canaria dirigida por Adrian Leaper que incluye La Divina Comedia, Ofrenda, Evocación y nostalgia de los molinos de viento y Seis pequeñas composiciones para coro y orquesta (ASv, DCA 1100, London, 2001). 
casual que sean éstos los más interpretados y de los pocos que se han llegado a grabar ${ }^{4}$. En el caso de la música sinfónica las escasas ediciones son bastante recientes, debidas al interés de la Editorial de Música Española Contemporánea ${ }^{5}$ de la música escénica tan sólo se ha editado el facsímil de la ópera de cámara Fantochines ${ }^{6}$. Se comprende así claramente las dificultades de difusión de la música del maestro Conrado del Campo, cuyo extenso legado musical -arrinconado en su archivo personal- había quedado inaccesible para músicos y estudiosos.

Ante esta precariedad de fuentes e interpretaciones no resulta extraño el escaso conocimiento de la figura de Conrado del Campo, que a pesar de su presencia e influencia en la música de su tiempo sigue siendo un gran desconocido para estudiosos y músicos. Además de las referencias en manuales genéricos, tan sólo el escritor Tomás Borrás - gran colaborador con el maestro en algunos de sus proyectos operísticos- realizó un breve repaso biográfico, escrito poco después de su fallecimiento dentro de una colección del Instituto de Estudios Madrileños ${ }^{7}$. La bibliografía sobre el maestro era así tan escueta, que su propio hijo Ricardo del Campo -un ingeniero nacido en 1919 que nunca se había dedicado a la música- decidió tras su jubilación escribir unos extensos apuntes que servirían para redactar una biografía, que quedó inédita. El compositor Miguel Alonso, discípulo de Conrado del Campo y uno de los más apasionados defensores de su memoria, recogió dicha biografía con la intención de completarla con vistas a su publicación, edición que finalmente no se realizó. Lo único que ha quedado de todo esto es el catálogo, que en sus diversas publicaciones sirve para poner un cierto orden en el complejo legado musical de Conrado del Campo ${ }^{8}$.

\section{LOS PRIMEROS AÑOS DE CONRADO DEL CAMPO (1895-1910)}

Nacido en Madrid en 1878, Conrado del Campo vivió desde dentro la actividad musical madrileña gracias a su actividad como instrumentista. Estudió violín y viola en el Conservatorio de Madrid con Jesús de Monasterio y José del Hierro, y ya desde muy joven trabajó en los fosos de algunos teatros de zarzuela, labor que inicia con sólo catorce años en el Circo Colón, para luego pasar por el Apolo y el Príncipe Alfonso. En 1896 ingresa en la orquesta del Teatro Real, formación en la que permanece como

4 El cuarteto $n^{\circ} 5$ es una obra compuesta entre 1907-1908 y publicada en 1923 por la Unión Musical Española, mientras que el $\mathrm{n}^{\circ} 13$, compuesto en 1949 , se ha publicado en 1990 por la misma casa editorial.

5 Las partituras disponibles en EMEC son: Fantasía castellana (1947) publicada en 1982, las dos partes de La Divina Comedia (1908-1910) en 2001 y Seis pequeñas composiciones para orquesta y pequeño coro sobre versos de Góngora (1927) en 2002.

6 Fantochines. Madrid, Fundación Juan March, 1990. Edición del facsímil realizada por Antonio Gallego; la ópera se estrenó en 1923.

7 Borrás, Tomás: Conrado del Campo. Madrid, Instituto de Estudios Madrileños, 1954. El breve folleto consta de 43 páginas y se incluyó como capítulo xIII dentro de un volumen titulado "Temas Madrileños", publicado en 1955.

8 Alonso, Miguel: Catálogo de la obra de Conrado del Campo. Madrid, Fundación Juan March, 1986. El catálogo sistematiza los apuntes realizados por Ricardo del Campo, que habían sido incluidos por Tomás Borrás en su estudio de 1954 a modo de inventario. Una revisión de este catálogo, adaptándolo a los criterios de la colección "Catálogos de Compositores", con coautoría de García Estefanía, Álvaro, fue publicada por la Sociedad General de Autores en 1998. 
viola solista hasta el cierre del teatro en 1925. Conrado del Campo también formó parte de diversas agrupaciones de cámara, como el famoso Cuarteto Francés entre 1903 y 1915, una de las formaciones que mayor impulso dio a la creación camerística española, reconvertido en Quinteto Madrid en 1919 con la incorporación de Joaquín Turina, o la agrupación de Unión Radio entre 1925 y 1929. También estuvo en la Orquesta Sinfónica de Madrid desde su fundación en 1904, siendo nombrado en 1908 Vicepresidente de la Junta Directiva, cargo que mantuvo hasta que en 1915 tuvo que renunciar a su atril por sus nuevas obligaciones como profesor del Conservatorio.

Esta ingente actividad interpretativa le lleva a vivir con intensidad la música madrileña del momento, conociendo a fondo el repertorio, tanto sinfónico como lírico y camerístico. Así, su wagnerismo no surge por peregrinaciones a Bayreuth o estudios con maestros extranjeros, sino a través de la interpretación diaria de los dramas líricos wagnerianos, que hacia 1910 causaban furor en el coliseo madrileño, con el estreno de Tristán, Parsifal y las diferentes jornadas de la tetralogía. Ya en 1915, tras el estreno de la ópera $L a$ tragedia del beso un crítico comentaba: "Conrado del Campo... ha oído mucha música y, especialmente, muchas óperas, cuyas partituras conoce al detalle: en una palabra, Conrado del Campo conoce el teatro y esto le permite caminar con segura planta, sin vacilaciones, sin infantilismo, sin inexperiencias."9

Todo esto supuso además un estrechísimo contacto con intérpretes y compositores. En el Teatro Real coincidió con los grandes directores del momento, como Luigi Mancinelli, Walter Rabl, Tullio Serafin, Karl Muck o Hermann Zumpe, entre otros muchos. Además vivió de cerca los problemáticos estrenos de las óperas españolas de Tomás Bretón, Emilio Serrano o Vives y compartió en 1909 el éxito de Margarita la tornera con Ruperto Chapí, gran amigo y figura admirada por el joven Conrado en estos años ${ }^{10}$. Especialmente interesante fueron los ensayos del Cuarteto Francés, que se realizaban en su casa -situada en el número 15 de la calle Arrieta, donde vivía con su padre y su hermana María- que se convirtieron en un punto de encuentro del Madrid musical de entonces. El médico Fausto Gavín, en unas declaraciones recogidas en los apuntes biográficos de Ricardo del Campo, recordaba el ambiente que se reunía alrededor del maestro:

"Figura popular en el todo Madrid de principios de siglo, era hombre de bondad, efusivo en su trato, de grandes simpatías, y su cultura y el prestigio de su nombre le habían logrado lugar preferente en el mundo musical y en la sociedad de entonces, que no tenía para él puerta cerrada. La casa de Conrado, aquel amplio cuarto suyo que abría sus balcones a la calle Arrieta, era conocido y buscado cenáculo artístico, escenario de sorpresas y acontecimientos, donde ensayaba el Cuarteto Francés, y donde acudían: Ruperto Chapí para terminar apresuradamente el tiempo final de uno de sus cuartetos, Enrique Granados leyendo al piano su partitura Goyescas, Walter Rabl -el director de orquesta alemán- con un clarinete bajo el

9 "La tragedia del beso", El País, 18.05.1915. Aunque el artículo no lleva firma, seguramente se trate de Rogelio Villar, por entonces crítico de dicho diario.

10 En honor a su amigo y maestro compuso una Fantasía sobre temas del maestro Chapí que se estrenó en el Teatro de la Zarzuela en 1913. Esta incluía temas de La bruja, El puñao de rosas, Margarita la Tornera, Curro Vargas y La venta de Don Quijote, selección que reflejaba su conocimiento y aprecio de la música de Chapí más allá de los tópicos habituales. En una entrevista posterior comentaba: "Fui discípulo del venerable D. Emilio Serrano [en el Conservatorio] y de aquel D. Ruperto Chapí, de imborrable recuerdo. De este último, a quien quise con todo cariño, conservo bastantes autógrafos y algunos originales de sus obras." "En el ático de Conrado del Campo", Ritmo, Madrid, 15.05.1930, p. 5. 
brazo para tocar con el cuarteto el Quinteto de Mozart, Arbós, Bretón, Saco del Valle, Manrique de Lara, y tantos otros."11.

A pesar de esta intensa actividad interpretativa, Conrado del Campo consiguió desarrollar su carrera compositiva creando un amplio catálogo de obras que pronto le situaron en primera fila de los músicos de su generación. Había ingresado en el Conservatorio de Madrid con once años, estudiando solfeo, violín y armonía, culminando sus estudios en las clases de composición de Emilio Serrano, donde recibió el primer premio en 1899. Ese mismo año la Sociedad de Conciertos de Madrid bajo la dirección de Tomás Bretón estrenaba el poema sinfónico Ante las ruinas, premiado en el concurso de jóvenes compositores convocado por dicha formación y considerado por su propio autor como su primer opus. Éxito que repite con una Misa Solemne en Re $m$ estrenada en Zaragoza ese mismo año. Sin embargo, el grueso de su producción de estos años lo constituyen sus ocho primeros cuartetos: $n^{o} 1$ en Re $m$ "Oriental" (1903), $n^{o}$ 2 en La (1906), $n^{o} 3$ en Do $m$ (1908), $n^{\circ} 4$ A buen juez mejor testigo (1906), $n^{\circ} 5$ Caprichos románticos (1908), $n^{\circ} 6$ Asturiano (1909), $n^{\circ} 7$ en Mi m (1911) y $n^{\circ} 8$ en Mi M (1913). Se trata de uno de los principales corpus cuartetísticos españoles, que completaría años más tarde -en la década de los cuarenta- con otros seis más. Aunque la mayoría de estos cuartetos permanecen inéditos y olvidados, las críticas del momento resaltaron su interés musical dentro de un estilo postromántico que no renunciaba a incluir lo español dentro de una densa textura contrapuntística y cromática. A título de ejemplo, podemos mencionar una breve referencia a la interpretación de un scherzo del cuarteto $\mathrm{n}^{\circ} 7$ que se califica como "página interesante, de cierto modernismo, de una gran complicación en sus procedimientos y con discretos y leves toques, apenas perceptibles, de nuestra musa popular"12; esta misma obra pudo escucharse en París en 1911 interpretada por el Cuarteto Lejeune.

Entre 1908 y 1910 emprende la composición de La Divina Comedia, una ambiciosa composición sinfónica inspirada en la famosa obra de Dante, que costó de dos partes: un prólogo y un amplio poema sinfónico que describe el infierno. El crítico Manrique de Lara comentó con entusiasmo que la segunda parte era "la más hermosa entre todas las composiciones de su autor y una de las más afortunadas de que puede envanecerse la moderna producción musical española"13. Ambos fragmentos fueron estrenados por la Orquesta Sinfónica de Madrid bajo la dirección de Enrique Fernández Arbós, constituyendo una de las referencias del sinfonismo postromántico español, una vía que huye de las referencias nacionalistas en favor de la tradición centroeuropea, relacionada con Richard Strauss. Su lenguaje es fuertemente wagneriano, con una armonía cromática, una organización sobre temas recurrentes a la manera de Leitmotiven y una elaborada textura contrapuntística e instrumental. No obstante, en composiciones sinfónicas posteriores vuelve a su interés por los aspectos nacionales, que tienen una presencia continua en la mayor parte de

11 Del Campo, Ricardo: [Biografía inédita de Conrado del Campo], p. 17. Manuscrito mecanografiado conservado en el legado de Miguel Alonso en la Sociedad General de Autores y Editores.

12 La reseña se refiere a un concierto del Cuarteto Francés en Zaragoza en marzo de 1913. Revista musical, Bilbao, año v, no 3 (marzo 1913), p. 79.

13 Manrique de Lara, Manuel: “Orquesta Sinfónica”, en El Mundo, 18.04.1910. 
su obra. Así sucede con los poemas sinfónicos Granada (1913), inspirado en una leyenda de Cantos del trovador de José Zorrilla, y Kasida (1920) sobre un poema de Tomás Borrás, tendencia que alcanza su culminación con Bocetos castellanos (1929). La dialéctica entre lo nacional y lo europeo es una constante en la creación de Conrado del Campo. Quizás la mejor definición de este estilo sea la de su amigo el hispanista y músico Henri Collet, quien en su clásico estudio sobre la música española comentaba:

“Conrado del Campo, qui, ayant écrit dans tous les genres avec la plus étincelante maîtrise, a su marquer au coin d'une très forte personalité des oeuvres extrêmement diverses dont l'évolution technique est un perpétuel émerveillement. Parti du straussisme le mieux assimilé, Conrado del Campo demeure encore aujourd'hui l'un des guides les plus avertis de la jeune école qui, en mainte occasion, a reçu ses conseils et en a retiré le meilleur profit." ${ }^{4}$.

\section{PRIMERAS EXPERIENCIAS EN LA ÓPERA: EL CASO DE EL FINAL DE DON ÁLVARO}

Conrado del Campo es un compositor de vocación lírica, a pesar de su fuerte dedicación a la música instrumental. Esto resulta lógico si pensamos que su principal trabajo estuvo durante cerca de treinta años en el foso del Teatro Real. Julio Gómez en un artículo de 1945 destacaba con apasionamiento este aspecto, lamentando a su vez un desconocimiento que mostraba la difícil situación musical española:

"Creemos, y esperamos, que la opinión general vendrá a darnos la razón, que en las obras dramáticas es en las que hemos de hallar las más conseguidas del compositor español; aunque por circunstancias especiales de todos conocidas, sean hoy las menos conocidas. El compositor español contemporáneo, aunque con grandes dificultades, puede hacerse oír en las salas de concierto. En el teatro imposible. Por esto se da el caso de que las obras más importantes y significativas de Conrado del Campo permanezcan, y solo Dios sabe por cuanto tiempo, sin alcanzar el escenario, en donde habrían de triunfar indiscutiblemente por sus altos méritos artísticos." ${ }^{\prime 15}$.

Dentro del complejo y desordenado catálogo de las obras líricas de Conrado del Campo ${ }^{16}$ se incluyen unas quince óperas, una docena de zarzuelas -la mayoría escritas en colaboración- y varias partituras para obras teatrales, en una producción que jalona toda su carrera, desde La Flor del agua-compuesta en 1909- hasta Lola la Piconera, estrenada en el Liceo de Barcelona en 1950. A pesar de las buenas intenciones de Miguel Alonso, este catálogo necesita una fuerte revisión, ya que se incluyen varias

14 Collet, Henri: L'essor de la musique espagnole au Xxe siècle. París, Editions Max Eschig, 1929, pp. 135-136. "Conrado del Campo, quien, habiendo escrito en todos los géneros con la más brillante maestría, ha sabido marcar el lugar de una muy fuerte personalidad de obras extremadamente variadas en las que la evolución técnica es una constante maravilla. Partiendo de un straussismo bien asimilado, Conrado del Campo permanece todavía hoy como uno de los guías más entendidos de la joven escuela que, en muchas ocasiones, ha recibido sus consejos con el mejor provecho."

15 Gómez, Julio: "Conrado del Campo, compositor dramático: La malquerida", en Música, año II, n 15, Madrid, 15.07.1945.

16 Alonso, Miguel: Catálogo de la obra de Conrado del Campo. Madrid, Fundación Juan March, 1986. 
referencias sobre fuentes fragmentarias y obras incompletas, además de algunas entradas erróneas. Esta confusión es fruto del carácter poco práctico del trabajo del maestro, quien no pensaba en un estreno o encargo concreto componiendo por puro amor al arte. Ya en una crítica de su primera ópera La Flor del agua de 1914 se comentaba este hecho:

"Músico tan inteligente como simpático, tan estudioso como modesto, es uno de los más formidables paladines de la música española. Pero no camina hacia este ideal haciendo antesala en el Ministerio para que una subvención oficial consagre en una partida del presupuesto un arte nonnato, sino que en su gabinete de estudio, sin alharacas intempestivas, trabaja en la creación de un teatro lírico nacional que hoy no existe más que en la mente de unos cuantos aspirantes a las prebendas burocráticas consiguientes." ${ }^{17}$.

Por mencionar sólo un par de ejemplos de estas dificultades, de la ópera en tres actos Leonor Telles -escrita sobre un libreto en portugués y pensada seguramente para Lisboa- tan sólo se han localizado algunos apuntes en el legado del compositor, a pesar de que el propio autor menciona en más de una ocasión que ya había completado la partitura de la ópera en 1917. En el caso de La malquerida -ópera en tres actos basada en el conocido drama de Benavente- la composición fue iniciada con vistas a la temporada del Teatro Real de 1925, aunque ante el cierre del teatro dejó inconcluso un trabajo que retomó durante los duros años de la Guerra Civil, terminando la partitura en 1938; no obstante, la ópera -que Julio Gómez en un brillante análisis calificó como "obra maestra"-18 nunca se ha llegado a estrenar.

La primera referencia a un trabajo lírico de Conrado del Campo la tenemos en la zarzuela en un acto Una vieja, antiguo libreto de Francisco Camprodón que había musicado con éxito Gaztambide en 1860. Fue compuesta como ejercicio del quinto curso de Composición en el Conservatorio en 1898, donde recibía clases de Emilio Serrano. Años después, Conrado del Campo anotó en el manuscrito un gracioso poema:

"La segunda zarzuela que hago en mi vida.

Dios quiera que mi muerte no se decida.

No me gusta este género por lo sencillo, mas no hay otro como este para el...bolsillo." ${ }^{19}$.

Años después también colaboró en otra pieza de género chico: Aires de la sierra, que se estrenó con discreción en el madrileño Coliseo del Noviciado en febrero de 1909. La composición había sido realizada en colaboración con Gregorio Baudot $(* 1884 ; \dagger 1938$ ), quien por entonces completaba sus estudios en el Conservatorio de Madrid antes de su marcha a Ferrol ${ }^{20}$. Conrado del Campo aprovechó parte del material

17 Navarro, Pedro: "Estreno de La Flor del agua", en España Nueva, 27.06.1914.

18 Gómez, Julio: "Conrado del Campo, compositor dramático: La malquerida", en Música, año II, n 15, Madrid, 15.07.1945.

19 "Según fichas de Ricardo del Campo con anotaciones de su padre". Alonso, Miguel; y García Estefanía, Álvaro: Conrado del Campo: Catálogo de composiciones. Madrid, SGAE, 1998, p. 33.

20 Carreira, Xoán M.: "Vida y obra del compositor Gregorio Baudot Puente”, en Revista de Musicología, v/1 (1982), pp. 
musical de esta pieza para su Cuarteto $n^{\circ}$ 2, que lleva el subtítulo de "Aires de la sierra". Esta zarzuela no fue más que una modesta colaboración, como realizó en numerosas ocasiones a lo largo de su vida, ofreciendo su ayuda más por amistad que por intereses artísticos ${ }^{21}$. Conrado del Campo en su intento de destacar las tradiciones españolas, indicó la importancia del género zarzuelístico -tanto grande como chico- "que tan sana alegría derramaba sobre la sensibilidad de las clases populares como animado y sentido resumen de su genuino espíritu y de sus pintorescas costumbres"22, según comenta en su discurso de ingreso en Real Academia de Bellas Artes de San Fernando. No obstante, siempre criticó la caótica situación del teatro musical español, como explicaba con claridad en una entrevista de 1930:

"Me asomé al teatro cuando ya se iniciaba la desorientación artística actual. Desorganización, inseguridad en las empresas, inestabilidad en las compañías, y lo que es más lamentable, trashumancia, vida bohemia en los géneros.

Las diversas familias teatrales no tienen actualmente en Madrid casa propia. Antaño, sí; cuando Chapí escribía sus admirables partituras, cada teatro era para un género determinado. En aquél, hallábamos la alta comedia o el drama; en éste, el sainete; en el de acá, la zarzuela grande; en el de allá, el género chico; y tal distribución, lógica, natural, prudente, eficazmente artística, manteníase desde el principio al final de cada temporada. ¿Hoy? Repase usted la colección de carteles de la mayor parte de los teatros. Inaugúrase el curso con una compañía de comedias, a esta le sucede una de operetas, viene al mes y medio a sustituirla El alcalde de Zalamea, un intermedio de cine, y, al iniciarse los primeros calores, surgen las populares producciones de Guerrero o de Alonso.

¿Cree usted que existiendo este magnífico desbarajuste se puede pensar seriamente en escribir una partitura?"23.

Así desde pronto Conrado del Campo sintió que el camino apropiado era el de la ópera, siguiendo los pasos de Tomás Bretón, Emilio Serrano -su profesor en el Conservatorio- y Ruperto Chapí. Un estímulo especial fue precisamente el éxito de Margarita la tornera en el Teatro Real a comienzos de 1909, que parecía marcar finalmente un camino favorable para la ópera española. Su primer trabajo de importancia en este sentido fue La Flor del agua, ópera que el propio Conrado del Campo calificó como "comienzo resuelto, decidido, de esa nueva etapa" ${ }^{24}$, haciendo referencia no sólo a esta ópera sino a la sensación general de impulso que vive la música española en esos años. Compuesta en 1909, no fue estrenada hasta 1914 debido al incendio del Teatro de la Zarzuela, que se produjo mientras se ensayaba esta obra. La

51-81. Sobre su participación en la ópera regional gallega véase CARREIRA, Xoán M.: "El nacionalismo operístico en Galicia", en Revista de Musicología, x/2 (1987), pp. 667-683.

21 Sin ánimo de ser sistemáticos, Conrado del Campo colaboró -seguramente en la orquestación de la que era un auténtico maestro- en zarzuelas de Ángel Barrios, Julio Gómez, Ernesto Rosillo, José Forns, Eduardo Martínez Torner o Eduardo Granados. Quizás el caso más conocido sea la instrumentación de uno de los actos de Doña Francisquita, ayudando a Amadeo Vives en las premuras para estrenar su zarzuela de mayor éxito. No obstante, Conrado del Campo no tenía reparo en participar en proyectos "menos edificantes" como en la revista El cabaret de la academia junto a Juan Tellería, uno de lo éxitos de Celia Gámez en el Teatro Eslava en 1927.

22 Del CAMPO, Conrado: Importancia social de la música y necesidad de intensificar su cultivo en España. Discurso de ingreso leído el 26 de junio de 1932. Madrid, Real Academia de Bellas Artes de San Fernando, 1932, p. 29.

23 "En el ático de Conrado del Campo", en Ritmo, Madrid, 15.05.1930, p. 5.

24 Del Campo, Conrado: "A propósito del estreno de La Flor del Agua”, en La Lira Española, 15.07.1914. 
ópera en un acto y tres cuadros más bien puede clasificarse como zarzuela ya que incluye largas partes habladas y números musicales cerrados. El libreto era de Víctor Said Armesto (*1874; †1914), escritor de amplia cultura, catedrático de la Universidad Central y Vicepresidente del Ateneo, que vivía por lo tanto muy alejado de los ambientes teatrales. Inspirado en leyendas bretonas y escandinavas, narraba la historia de amor entre la princesa Floshilda (soprano) y un falso juglar que resulta ser el príncipe Conrado (barítono), quien consigue de esta manera seducirla y superar la oposición del padre; el título hacía referencia al valle al que bajan los enamorados en la noche de San Juan, lugar lleno de ninfas acuáticas y gnomos, escenario fantástico que constituía uno de los números musicales más logrados. El tema por su ambientación fantástica y romántica -que remite a un idealizado mundo medieval- puede guardar cierta relación con el mundo wagneriano. Musicalmente, Conrado del Campo utiliza algunos rasgos wagnerianos como el tratamiento dramático de las voces -tanto en el extenso dúo de la pareja protagonista como en el monólogo inicial de Floshilda- y en la utilización de motivos recurrentes a la manera de Leitmotiven. Incluso algunos detalles recuerdan momentos wagnerianos, como comentaba el crítico del diario $A B C$ sobre el mencionado dúo, que "traduce al modo wagneriano los armoniosos ritmos de la floresta, es de una riqueza y de un colorido orquestal sencillamente admirables." ${ }^{25}$ No obstante, la ausencia de carácter épico y el carácter discontinuo de la partitura acercan más esta ópera al mundo superficial del modernismo de su época, lo que llevó a algunos críticos a buscar otra referencia en Debussy. En este sentido, Rafael Rotllán en El Debate comentaba la riqueza de los recursos musicales:

"El egregio autor es un técnico formidable. La armonización no tiene para él dificultades, ni la orquestación guarda secretos, ni en punto a sonoridades se le oculta nada. Los procedimientos más modernos le son familiares y sigue sus pasos y son sus maestros Bach, Haydn, Mozart, Beethoven, Wagner, Strauss y Debussy. De una inspiración honda, ardentísima, quizás algo sombría, y desde luego melódica, como buen latino que es; de una gracia y elegancia y hasta desgarro netamente españoles, padeció a veces, si no nos engañamos, igual que Albéniz, el sarampión del «debussysmo», y se empeñó en ahogar las melodías y en romper las frases, arrojando sobre ellas, no bien iniciadas, puñados de sonoridades y carretadas de polifonía armónica." 26 .

Mayor resonancia tuvo el que fue su primer estreno operístico, El final de Don Álvaro, drama lírico en un acto y dos cuadros, que dada su extensión se representó en el Teatro Real con un intermedio a la manera de una obra en dos $\operatorname{actos}^{27}$. Había sido compuesto en dos o tres meses -entre junio y septiembre de 1910- en la localidad portuguesa de Cascaes, en cuyo Casino actuaba durante los veranos con el Cuarteto Francés. El texto había sido escrito por Carlos Fernández Shaw $(* 1865 ; \nmid 1911)$, uno de los más prestigiosos libretistas del teatro lírico español de su momento, cuya relación con Conrado del Campo se había estrechado a través del contacto con Chapí ${ }^{28}$. Este fue uno de los más prolíficos colaboradores del músico de Villena, en libretos

25 "Los estrenos: La Flor del Agua", en $A B C, 27.06 .1914$.

26 Rotllán, Rafael: "Estrenos: La flor del agua", en El Debate, 27.06.1914.

27 Aunque en la partitura original manuscrita pone "un acto y dos cuadros", en la portada de la edición del libreto se indica "drama lírico en dos actos" (Madrid, Sociedad de Autores Españoles, 1911).

28 Véase, FernándeZ-Shaw, Guillermo: Un poeta de transición. Vida y obra de Carlos Fernández. Shaw. Madrid, Gredos, 
como La Revoltosa, Las bravías o la mencionada ópera Margarita la tornera, entre otras muchas; según Luis G. Iberni de la colaboración entre Chapí y Fernández Shaw salieron "a la escena madrileña algunas de las aportaciones de mayor calado en la historia de la zarzuela" ${ }^{29}$. Además fue uno de los pocos libretistas interesado en la ópera española, escribiendo los libretos de La vida breve de Manuel de Falla, El certamen de Cremona de Tomás Bretón, Colomba de Amadeo Vives o La maja del rumbo de Emilio Serrano. Debemos imaginar así cómo Conrado del Campo vivió muy de cerca el interés de todos estos músicos por la ópera -todas las mencionadas fueron compuestas en esta primera década del siglo-, y con especial intensidad la trascendencia del éxito de Margarita la tornera en 1909. Desgraciadamente en marzo de 1911 Carlos Fernández Shaw no pudo asistir al estreno de la ópera de Conrado del Campo, ya que se encontraba convaleciente de una enfermedad que le llevaría a fallecer tres meses después.

La labor literaria de los libretos operísticos de Carlos Fernández Shaw ha sido discutida en diversas ocasiones. Su obra poética mantenía la grandilocuencia romántica decimonónica, como se puede ver especialmente en sus últimos libros de poemas como Poesía de la Sierra (1908) o El Alma en pena (1909), donde formalmente conserva las formas métricas tradicionales ${ }^{30}$. Esta vena poética no resultó siempre adecuada para sus textos operísticos, especialmente cuando no existía un colaborador que colocase sus versos en el adecuado contexto dramático. Julio Gómez al analizar el problema del libreto en la ópera española lamenta en Carlos Fernández Shaw la "expresión verbal demasiado abundante, a la que le llevaba su exuberante temperamento", particularmente en los libretos para Conrado del Campo, donde "se hace patente la falta de disciplina, la total carencia de formas producida por el abandono de las consagradas por el uso en la ópera tradicional y no hallar las concretas de drama lírico moderno con las que habría que haberlas sustituido"31. En una línea similar, Miguel Salvador criticó tras el estreno de El final de Don Álvaro que uno de los principales problemas de la ópera española era que "no tenemos quienes produzcan libretos, tales como las corrientes crítico-musicales modernas los exigen", mencionando como modelo los dramas de Maeterlinck, cuyo estilo estaba muy alejado de los textos de Fernández Shaw:

“¡Estos [poemas] pueden inspirar dramas líricos modernos, los que nosotros producimos no! Eso de explicar los antecedentes del drama es lo que nos mata, pues explicamos mucho los dramas y no ocurren ni suceden ellos; no tenemos en cuenta lo que debe de callar la letra, lo que debe traducir y lo que no puede traducir la música; conocen nuestros poetas preciosamente el lenguaje hablado, el musical para ellos es un arcano!..." 32 .

1969. Además, Lozano, Pilar: "Archivo epistolar de Carlos Fernández Shaw”, en Revista de Literatura, xxII, n $43-44$ (juliodiciembre 1962), Madrid, Instituto Miguel de Cervantes de Filología Hispánica, pp. 125-210. No debe despistarnos que en este extenso epistolario - que recoge cartas de Chapí, Emilio Serrano y Bretón, entre otros músicos- no figure ninguna carta de Conrado del Campo, ya que se puede explicar tanto por la cercana presencia en Madrid de ambos como por la brevedad de su relación ante el temprano fallecimiento del escritor.

29 Gracia Iberni, Luis: Ruperto Chapí. Madrid, Instituto Complutense de Ciencias Musicales, 1995, p. 231.

30 Además de las ediciones originales, existen dos interesantes recopilaciones de la obra poética de FERNÁNDEZ-SHAW, Carlos: El canto que pasa: antología poética (1883-1911), Madrid, M. Aguilar, 1947 (con prólogo de su hijo FERNÁNDEZ-SHAW, Guillermo) y Poesías completas, Madrid, Gredos, 1966 (con introducción y estudio de FernándeZ Almagro, Melchor).

31 Gómez, Julio: Los problemas de la ópera española. Discurso de ingreso leído el 17 de junio de 1956. Madrid, Real Academia de Bellas Artes de San Fernando, 1956, p. 36.

32 Salvador, Miguel: "Madrid: Teatro Real", en Revista musical, Bilbao, año III, no 4 (abril 1911), p. 91. 
El libreto de El final de Don Álvaro desarrollaba los episodios finales del famoso drama del Duque de Rivas, cumbre del Romanticismo teatral español. En el inicio vemos a Don Álvaro retirado en un convento franciscano donde expía sus anteriores culpas; allí le encuentra Don Alfonso -el hermano de Doña Leonor- dispuesto a vengar la serie de desafortunadas muertes de su familia, aunque en el enfrentamiento con Don Álvaro fallece en la lucha. En el segundo cuadro asistimos al desenlace con el encuentro final entre Don Álvaro y Doña Leonor, quien retirada en una ermita cercana descubre la trágica muerte de su hermano, lo que provoca el suicidio del protagonista que se arroja desde lo alto de la montaña. La elección de sólo el final de la obra original posibilitaba concentrar la acción en el episodio central y más dramático, evitando la difícil adaptación operística que sin duda planteaba un drama de tanta variedad y dispersión como el del Duque de Rivas. Según Valbuena Prat, "es difícil encontrar un drama en el teatro universal tan rico en tipos diversos, en ambientes y paisajes de todo orden" 33 . No en vano son conocidos los problemas de Verdi con La forza del destino, ópera que a pesar de sus sucesivas revisiones nunca consiguió alcanzar un resultado satisfactorio; el propio Verdi nunca se sintió a gusto con el final que cambió para representar la salvación final del protagonista ${ }^{34}$. De hecho, la ópera de Verdi -una de cuyas revisiones contó con la propia presencia del compositor en el Teatro Real de Madrid en 1863- nunca había llegado a asentarse en el repertorio. En Madrid no se había representado desde marzo de 1893, año en que la había cantado en el Teatro Real el gran tenor Francesco Tamagno ${ }^{35}$. Ni el público -ni prácticamente Conrado del Campo- conocían la ópera de Verdi más que por referencias lejanas, por lo que no resultaba tan extraño -como nos pueda parecer hoy- el interés de un compositor español por transformar en ópera el famoso drama del Duque de Rivas. De hecho, las críticas aparecidas tras el estreno de El final de Don Álvaro de Conrado del Campo tan sólo hacen referencia a la ópera de Verdi de manera tangencial y en ningún caso se intenta una comparación entre ambas óperas.

El interés de Conrado del Campo por el drama del Duque de Rivas podía parecer anacrónico hacia 1910, en un momento en que la crítica de la Generación del 98 atacaba con dureza las tradiciones románticas españolas. Azorín en sus ácidos comentarios de Rivas y Larra (1916) había comentado que el Don Álvaro era "una lógica, natural continuación del drama de Calderón y de Lope, con los mismos procedimientos, la misma falta de observación, la misma incoherencia, la misma superficialidad"36. El posicionamiento de Conrado del Campo a favor del drama del Duque de Rivas reflejaba su atracción hacia el siglo XIX, en una postura que le relaciona con el denominado Postromanticismo, movimiento que prolonga la estética romántica a las primeras décadas del siglo xx. En este sentido, el propio Conrado del Campo en unas notas enviadas a la prensa poco antes del estreno destacaba la intensidad

33 Valbuena Prat, Ángel: Historia de la Literatura Española. Barcelona, Gustavo Gili, 1968, tomo III (Siglo xVIII y Romanticismo), p. 144.

34 Véase la acertada síntesis de este tema en el capítulo sobre La forza del destino de Mila, Massimo: El arte de Verdi. Madrid, Alianza Música, 1992, pp. 145-158

35 En el Teatro Real La forza del destino de Verdi se cantó en seis temporadas diferentes con un total de 42 representaciones, la mayoría en la década de 1860. Turina Gómez, Joaquín: Historia del Teatro Real. Madrid, Alianza Editorial, 1997, pp. 319 y 411.

36 Citado en el estudio introductorio de SÁNCHEZ, Alberto, a la edición crítica de Don Álvaro o la fuerza del sino, Madrid, Cátedra, 2001, pp. 33-34. 
y el interés dramático del drama del Duque de Rivas, una obra por la que siempre había tenido especial predilección desde muchacho:

“El final de D. Álvaro es un drama, o quizás pudiéramos llamarlo mejor un poema escénico, en que se resume y sintetiza la acción romántica y vigorosa del drama famoso del Duque de Rivas, una de las obras del pasado siglo en que mejor se refleja y caracteriza el carácter legendario de nuestra raza con sus arrebatos, sus desalientos, sus impulsos de pasión desbordada, que por encima de la razón salta, osada, insensatamente, hacia un ideal confuso que se oculta allá en la mente heroica, en el sacrificio que redime. Obra extraña cuyo Final causóme siempre honda impresión y en el que hallé elementos poderosos de musicalidad, dentro del marco escénico" ${ }^{37}$.

Años después, en su discurso de ingreso en la Academia de Bellas Artes de 1932, reflexionaba sobre el teatro romántico español, lamentando que sólo había sido potenciado musicalmente en la ópera italiana, a pesar de sus claros fundamentos españoles:

"Y es curioso en verdad ver cómo nuestros poetas románticos, que en el ambiente español bañaban sus pensamientos acudiendo a las puras fuentes del pasado, tradiciones, leyendas y romances históricos, en busca de elementos de inspiración para sus obras y logrando crear bajo el influjo animador de esos venerables testimonios del puro sentimiento de la raza obras como El Cristo de la Vega y Margarita la Tornera, Zorrilla; los Romances y Don Álvaro, el Duque de Rivas; no percibieran el profundo sentido, la ferviente corriente evocadora de fondo musical, la intensidad romántica que en su seno encerraban esas mismas tradiciones y desconocieran o, al menos, no se interesaran por el caudal de nuestras canciones, caminando en pos, cuando de música se trataba, de la melodía italiana, del corte, acento y expresión de la ópera romántica, sin advertir la oposición profunda que entre aquellas fuentes poéticas a que ellos acudían en busca de legítimas inspiraciones y el arte italiano existía, ni, menos aún, presentir la honda corriente de original sentido de nuestras viejas tonadas y danzas aldeanas, oscuramente adormecidas por culpa del indiferentismo sentimental y de la débil potencia creadora de la Nación durante siglos" 38 .

De esta manera, Conrado del Campo veía la obra del Duque de Rivas desde una óptica claramente nacionalista interesándole no sólo su potencial escénico y dramático sino también su inserción en las tradiciones españolas. Para ello pidió al libretista que incluyese dos episodios de carácter popular que sirviesen no sólo para ofrecer un adecuado contraste a la violenta acción sino también la oportunidad de una caracterización más española. Así, en medio de la sierra donde se ha retirado Doña Leonor aparecen unas pastoras y un coro popular comentando sobre la misteriosa habitante de la ermita, en un pasaje construido sobre un ritmo ternario de claras resonancias españolistas. Según Joaquín Fesser en El Correo, "la escena de las pastoras es un modelo de finura, un acierto completo, basado en el canto popular español, admirablemente tratado en la tendencia de harmonización moderna" 39.

37 Del CAmpo, Conrado: "Impresiones del autor", en Revista musical, Bilbao, año III, no 1 (enero 1911), p. 9. Según se menciona en el artículo estas "rápidas notas sobre su obra" habían sido enviadas también a la Revista Musical Catalana.

38 Del CAMPo, Conrado: Importancia social de la música..., p. 10.

39 Joachim [Fesser, Joaquín]: “Teatro Real, El final de Don Álvaro”, en El Correo, 5.03.1911. 
El otro pasaje fue un canto de trilla entonado desde la lejanía por un gañán, que escucha Don Álvaro al final de la primera escena de la ópera (Ejemplo 1). El propio personaje comenta al oírlo que este alegre canto le devolvía al mundo real que le rodeaba alejándole momentáneamente de sus inquietudes ${ }^{40}$. Musicalmente, frente al lenguaje denso y cromático de otros pasajes, aquí el compositor prefiere sonoridades más desnudas -sobre tríadas con séptimas no funcionales- y una armonización más diatónica de sabor modal evitando la sensible, sobre un Sol mixolidio.

\section{EJEMPLO 1}

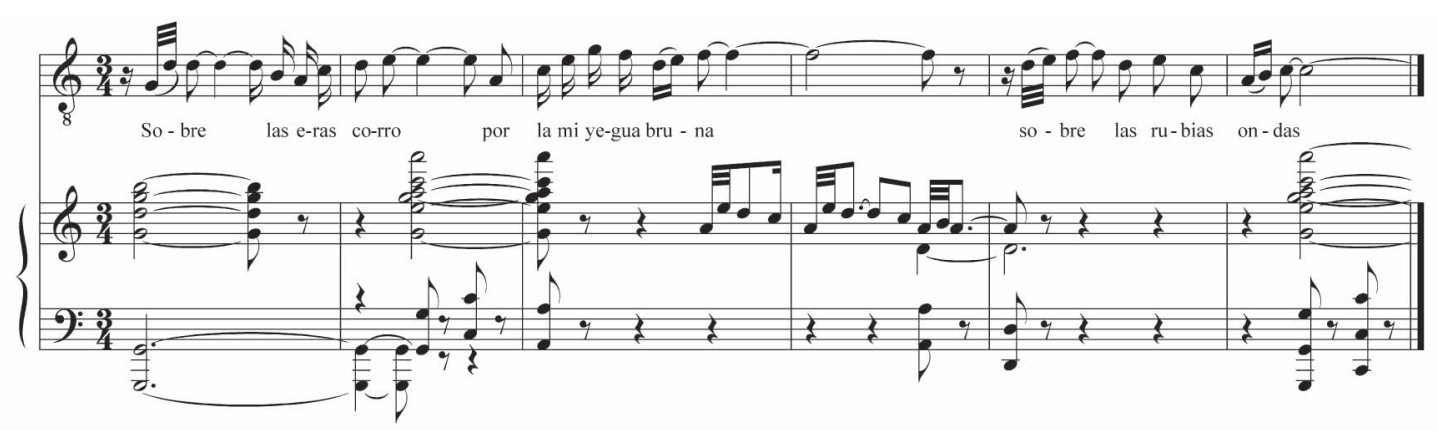

Según el propio compositor -en una carta enviada al periódico España Nueva- uno de los aspectos que más le interesó fue precisamente darle a la ópera una orientación española, buscando "el carácter adecuado, castizo, propio, que era preciso imprimir a la orquestación durante toda la obra, pero más aún en las escenas intercaladas de "sabor" popular que debían ofrecer como un "marco" de sabor local, de ambiente español, "serrano", al dramático asunto del poema" ${ }^{41}$. Este carácter nacionalista de la primera ópera de Conrado del Campo fue destacado por los principales críticos, a pesar de que el lenguaje predominante era el wagneriano. Para Henri Collet -que analizó con brillantez El final de Don Álvaro en una conferencia en el Ateneo- era una auténtica ópera española, digna de pasar las fronteras, ya que "marca un punto culminante en la historia de la música dramática española"42. De la misma manera, un crítico tan fuertemente wagneriano como el compositor Manuel Manrique de Lara reconocía el interés de estos elementos de carácter español: "Sin embargo, en su hermosa obra yo prefiero aquellos otros, como el final del primer cuadro, como las escenas pastoriles del cuadro segundo, en que sobre la exquisita y magistral labor de la orquesta y la habilidosa intervención de las voces, se extiende un tenue velo de bucólica poesía”43.

40 "Canto de trilla alegre, / sensaciones del mundo me devuelves. / Las visiones se borran, / con este sol, del que temí sin tino. / Mis ánimos recobran / gracias a vos, Padre, nuevos bríos." Fernández-Shaw, Carlos: El final de Don Álvaro. Madrid, Sociedad de Autores Españoles, 1911, p. 10.

41 Del Campo, Conrado: "El estreno de esta noche", en España Nueva, 04.03.1911.

42 Collet, Henri: "El final de Don Álvaro", en Nuestro Tiempo, Madrid, año ix, no 147 (marzo 1911), p. 348. El artículo recoge una conferencia-concierto en honor al maestro Conrado del Campo con motivo del estreno de su primera ópera, dada en el Ateneo de Madrid el viernes 10 de febrero de 1911.

43 Manrique de Lara, Manuel: “El final de Don Álvaro”, en El Mundo, 05.03.1911. 
No obstante, estos episodios suponen tan sólo un contraste dentro de El final de Don Álvaro, una ópera en la que el lenguaje wagneriano permitía desarrollar la gran intensidad de la acción dramática original. En este sentido, Joaquín Fesser comentaba:

"La factura, el trabajo armónico y melódico, el trato de las voces, el color instrumental, están hechos con entera libertad, sin una sola concesión a lo convencional ni a lo rutinario. Su orientación es la de Wagner y sus sucesores, sin el menor servilismo ni sectarismo, sin asomo de imitación o de plagio. La melodía y la sinfonía son continuas, residiendo en esta última el comentario anímico íntimo, y en aquella la expresión lírica verbal siempre o casi siempre declamada, sin cuadraturas, sin moldes, sin estrofas, sin obligadas simetrías ni melismas románticos”44.

El punto de partida estilístico de El final de Don Álvaro es el del drama lírico wagneriano, con todas sus implicaciones musicales, como la continuidad de la acción -lejos de los números más o menos cerrados de la tradición italiana- y la constante presencia de la orquesta comentando el desarrollo dramático. El lenguaje armónico es bastante cromático, especialmente en momentos de gran intensidad como la lucha entre los dos rivales, el trágico final o la amenazadora tormenta que preside las tensas reflexiones de Leonor. No obstante, las referencias tonales nunca se pierden y contribuyen a articular las diferentes escenas. Además, debe destacarse la riqueza instrumental, fruto de una gran actividad contrapuntística de todas las partes. El uso de Leitmotiven no es excesivo, debido lógicamente a que el escaso desarrollo argumental limita la aparición de recuerdos y reminiscencias en la acción. Al contrario que Wagner no construye todo el tejido sinfónico sobre los Leitmotiven, sino que los utiliza puntualmente de manera poética y evocadora. Así sucede con un tema que se relaciona con la pasión por Leonor, que ya se presenta en los primeros compases de la partitura (Ejemplo 2A), reapareciendo en otros momentos significativos, como en el recuerdo de Don Álvaro por su amada (Ejemplo 2B), antes de la primera presentación de la propia Leonor en el segundo cuadro o cuando ésta descubre en el final el asesinato de su hermano (Ejemplo 2C); en todos ellos apenas tiene transformaciones y se presenta en la misma tonalidad de Mi Mayor.

\section{EJEMPLO 2A}

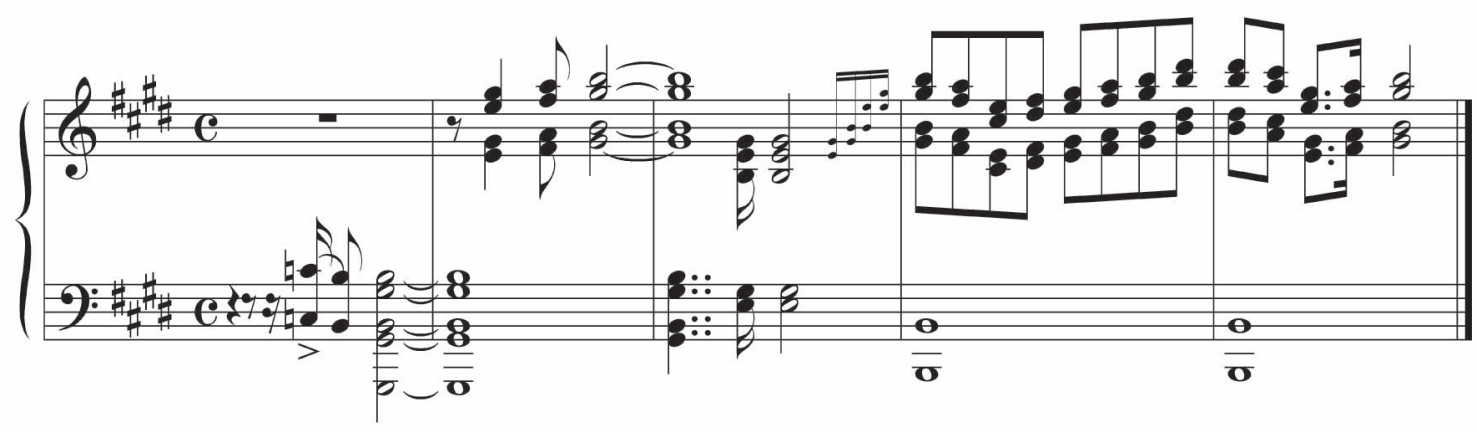

44 Joachim [Fesser, Joaquín]: “El final de Don Álvaro”, en El Correo, 05.03.1911. 


\section{EJEMPLO 2B}

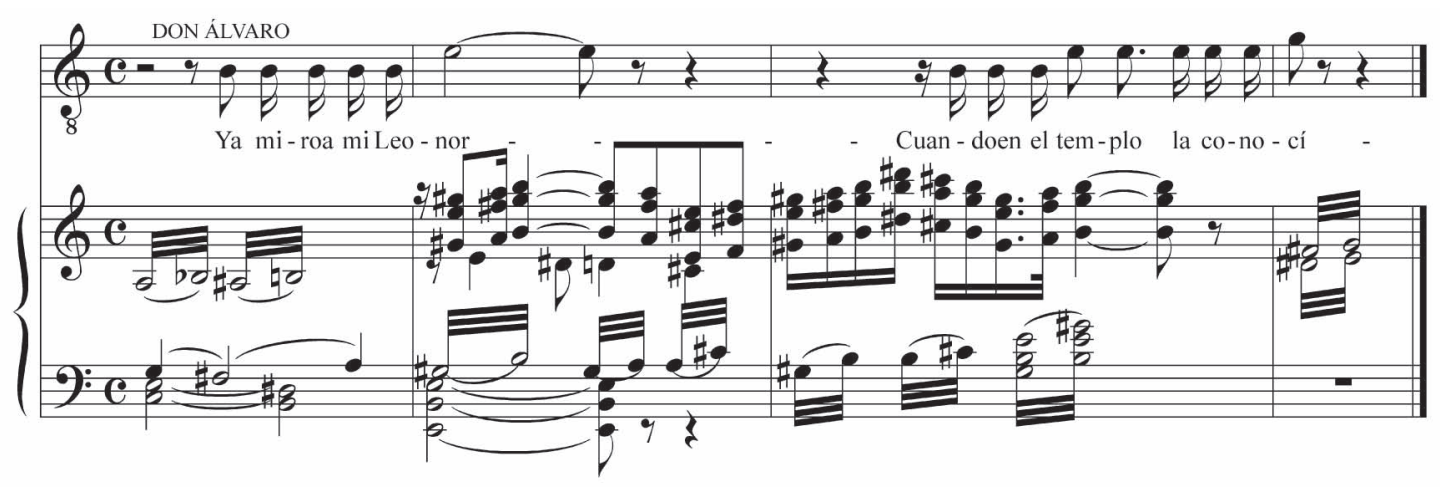

\section{EJEMPLO 2C}

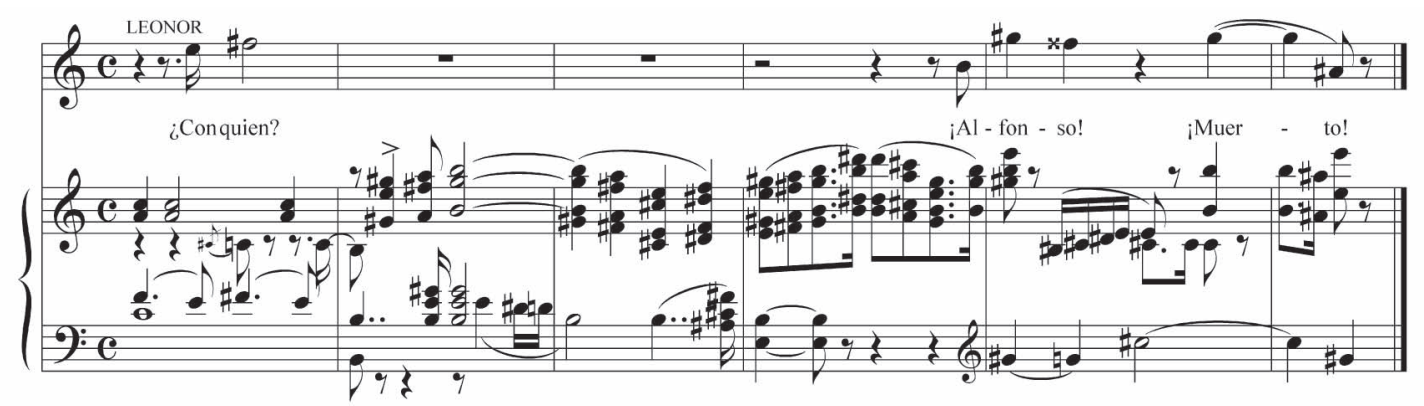

También resulta wagneriana la utilización de las voces en los tres personajes principales: Doña Leonor (soprano), Don Álvaro (tenor) y Don Alfonso (barítono). Mientras que este último tan sólo participa en su tenso enfrentamiento con el protagonista, los dos primeros tienen además sendos monólogos: en el primer cuadro Don Álvaro entona un grandilocuente canto al Sol, mientras que en el segundo Doña Leonor canta una plegaria a la Virgen pidiendo protección en su retiro. A estos habría que añadir -con carácter secundario- el Padre Guardián, una pastora, las tres cabreras (Curra, Nieves y Fuentsanta) y la voz del gañán, además del coro. Los dos protagonistas afrontan largos papeles, sobre líneas declamatorias, donde debe destacarse el continuo uso de la denominada zona de paso de la voz, a la manera de las voces wagnerianas. En este sentido, el papel de Don Álvaro se encuentra cerca de los modelos del Heldentenor, tanto por su tesitura como por la dureza de sus participaciones.

Las especiales circunstancias del estreno -al final de la temporada, pocos ensayos y cantantes secundarios- no propiciaron el mejor resultado interpretativo, lo que llevó a que algunos aspectos fueran poco comprendidos, como sucedió con el tratamiento vocal. En este sentido, resulta de interés el comentario aparecido en el diario El Debate: 
"La orquestación en el segundo cuadro es magnífica y resulta una labor de un gran maestro, poniendo Del Campo de manifiesto su gran talento musical; si las voces las tratara con el acierto que lo hace en la orquesta, mucho mayor éxito le hubiera acompañado. La tesitura del tenor y soprano es demasiado aguda, y sobre todo teniendo que pronunciar palabras en tan altas notas; así es que pocos artistas podrán resistir tales tesituras, y eso principalmente será la causa mayor para que su ópera no tenga tantos admiradores entre los cantantes" ${ }^{\prime 4}$.

El papel de Don Álvaro había sido encomendado al tenor gerundense Amador Famadas, quien a sus veintiocho años realizaba los primeros pasos de una carrera que le llevaría posteriormente a triunfar en Europa y Estados Unidos en papeles dramáticos como Ramadés de Aida ${ }^{46}$. De hecho, en el Teatro Real apenas había cantado esa temporada, habiendo quedado ensombrecido por la maestría de Francisco Viñas, quien había alcanzado uno de sus mayores éxitos con Tristán e Isolda, presentada por primera vez en el Teatro Real apenas un mes antes. La inmadurez de Famadas y la rapidez de la puesta en escena de El final de Don Álvaro le causaron algunas dificultades de las que hay constancia en algunos comentarios de la crítica. Aunque según el diario El Mundo "venció con gran acierto las tremendas dificultades de su parte y obtuvo grandes aplausos"47, en España Nueva se comentó con cierto tono de crítica que "tiene una parte muy aguda e hizo cuanto pudo por salir airoso de su papel”48. La joven Beatriz Ortega Villar había triunfado en años anteriores en los papeles más líricos del repertorio wagneriano como Elsa o Elisabeth, por lo que defendió con dignidad su papel de Doña Leonor, "apasionada y poéticamente dramática, cuya voz y cuyo arte tuvo el supremo encanto de cuanto es espontáneo y juvenil”49. El reparto se completaba con el norteamericano Benedetto Challis, que realizó un gran esfuerzo para cantar en castellano con su voz grande y potente, que ya había mostrado al público madrileño en la interpretación del Kurwenal del Tristán.

El final de Don Álvaro se estrenó en el Teatro Real en los últimos días de la temporada 19101911, contando con la presencia de la familia real. Se representaba un poco por compromiso debido a que su autor además de un músico reconocido era miembro de la orquesta del foso. La orquesta la dirigió Ricardo Villa, mientras que Conrado del Campo permaneció en su atril como primer viola, saludando al final con todos los intérpretes. La mayoría de las crónicas mencionan el éxito de la obra. Ernesto de la Guardia en El País concluye tras escuchar el ensayo general que "es una producción seria, sincera e interesante de cuantas han compuesto nuestros músicos en estos últimos años" que en El Globo se lamentaban que "el triunfo demostraba que era digna de haberse estrenado de muy diversa manera de cómo lo ha sido" ${ }^{51}$. Tan sólo se realizaron tres funciones para dejar olvidada la

45 El caballero del Cisne: "Los estrenos de anoche: Real", en El Debate, 05.03.1911.

46 Tras estudiar en Milán, había debutado precisamente con el papel de Radamés en un festival de verano en el Teatro de las Arenas de Barcelona en 1909. Martín DE SAgarmínAga, Joaquín: "Famadas, Amador", en Diccionario de cantantes líricos españoles. Madrid, Acento Editorial, 1997, p. 143.

47 Manrique de Lara, Manuel: "El final de Don Álvaro", en El Mundo, 05.03.1911.

48 Navarro, Pedro: "Noches de estreno en el Real", en España Nueva, 05.03.1911.

49 Manrique de Lara, Manuel: "El final de Don Álvaro", en El Mundo, 05.03.1911.

50 De la Guardia, Ernesto: "El Final de Don Álvaro", en El País, 04.03.1911.

51 F. "Del Real", en El Globo, 05.03.1911. Posteriormente enumera las dificultades de la producción: "escasos ensayos, premuras de tiempo, pobreza de decorado y vestuario y faltando tres funciones solamente para terminar la temporada." CoLLET, 
partitura en el cajón del estudio de Conrado del Campo. Su amigo Henri Collet realizó una traducción al francés, que se ha conservado anotada en algunos de los manuscritos de la Sociedad General de Autores, seguramente con vistas a intentar una interpretación en el extranjero que no llegó a fructificar. No obstante, había supuesto la primera experiencia sobre el teatro de una larga carrera operística, que el maestro continuaría a pesar del desinterés general -público, intérpretes y empresa- hacia las óperas españolas.

\section{RESONANCIAS TRISTANESCAS EN LA TRAGEDIA DEL BESO}

A finales de la primera década del siglo xx Madrid vive una auténtica fiebre wagneriana. Las obras del maestro de Bayreuth se interpretan en conciertos y teatros de ópera y la cuestión wagneriana es debatida más allá de los círculos musicales. A modo de ejemplo podemos mencionar dos conferencias celebradas en el Ateneo de Madrid, dadas por Henri Collet -el hispanista francés, tan amigo por estos años de Conrado del Campo- que bajo el título de Los paisajes de Wagner reflexionó sobre diferentes aspectos de la psicología de los dramas líricos ilustrando su explicación con numerosos ejemplos sobre el piano ${ }^{52}$. En el Teatro Real se celebraron durante la temporada 1910-1911 los denominados "miércoles wagnerianos", a los que acudían -según cuenta Subirá- los devotos de los dramas líricos con la partitura dispuestos a seguir la interpretación, aunque ante la oscuridad de la sala tuvieron que pedir más iluminación durante las representaciones ${ }^{53}$.

Gran parte de la culpa de esta moda la tiene la renovación de la gestión del Teatro Real, con la llegada de la empresa de Luis Calleja y Antonio Boceta en 1907, que en sus seis años al frente del teatro mostraron un especial interés en renovar el repertorio e impulsar el wagnerismo; detrás estaba la figura de Luis París, director artístico y uno de los principales defensores de las obras de Wagner, quien ya en 1899 había revolucionado el Teatro Real para la compleja presentación de La Walkyria. De hecho, José Subirá en su clásico estudio sobre la historia del Teatro Real titula el capítulo dedicado al periodo 1910-1913 "el apogeo wagneriano" 54 . Uno de los retos de estas temporadas fue el completar la representación de la tetralogía El anillo del Nibelungo, cuyos cuatro dramas líricos se vieron sin orden, en función de las posibilidades de programación, dirigidos por el maestro Walter Rabl. Las condiciones artísticas fueron bastante deficientes, especialmente en El ocaso de los dioses, que se estrenó en marzo de 1909 con tantos cortes que hasta se eliminó el papel de Alberich. Paradójicamente, la última parte en conocerse fue el prólogo El oro del Rhin, que se estrenó en marzo de 1910, en cuyo montaje existieron algunos problemas, como la salida de Erda “que tardó en ascender de sus propias entrañas más tiempo

\footnotetext{
Henri ("El final de Don Álvaro", en Nuestro Tiempo, no 147, (1964), pp. 347-348) señala que la celda del primer cuadro "se reduce a un lienzo sin pintar", mientras que para el agreste monte del segundo cuadro se reutilizaron "los tétricos peñascos de la Tetralogía y los ramajes que aparecen Tristán.”.

52 C. R. [De Roda, Cecilio]: "Madrid", en Revista musical, Bilbao, año I, nº 6 (junio 1909), p. 138.

53 SubIRÁ, José: Historia y anecdotario del Teatro Real. Madrid, Editorial Plus Ultra, 1949, p. 642.

54 SubIRÁ, José: Historia y anecdotario del Teatro Real..., pp. 631-655.
} 
del que señaló es sus momentos rítmicos, musicales y proféticos el poeta-músico Wagner"55 o "los deficientísimos intérpretes de los gigantes, que estropearon y ridiculizaron las dos escenas en que intervienen" 56 .

Sin embargo, el punto culminante del wagnerismo madrileño llegó en febrero de 1911 con el estreno de Tristán e Isolda, que supuso "un triunfo personal de la empresa, artístico y económico"57, tanto por la novedad de la obra como por la excelente interpretación de la soprano Cecilia Gagliardi y el tenor Francisco Viñas. La prensa llegó a comentar que "jamás se ha hecho, ni se ha cantado, ni se ha interpretado, ni se ha puesto en el Real una obra de Wagner con tal ajuste, con tal respeto, con fidelidad semejante, con entusiasmo y conocimiento así de las notas como del poema"58. La última representación de Tristán, un día antes del estreno de El final de Don Álvaro, se sintió como el cierre de la temporada, cuyo éxito reflejaba la fuerza alcanzada por las óperas de Wagner en Madrid; en el diario La Época se recogía el delirio del público:

"Ovaciones sin cuento comentaron con elocuencia, al terminar los actos, el admirable trabajo de los tres magníficos artístas [la Gagliardi, Viñas y el director Marinuzzi]. No menos de 15 veces se alzó el telón en honor de ellos al final de la ópera, y cuando descendió la vez postrera, fue para posarse sobre espesa alfombra de flores y coronas, ofrendadas al talento y al arte por la admiración y el entusiasmo del público" 59 .

Fruto de estas representaciones fue la fundación de la Sociedad Wagneriana de Madrid, durante la primavera de 1911, que llegó a reunir en poco tiempo 1.100 socios, entre los que estaba el propio Conrado del Campo. En realidad ésta surgía ya tarde cuando el éxito de las obras de Wagner hacía innecesario cualquier tipo de difusión y proselitismo. No obstante, en sus dos años de existencia se organizaron algunas conferencias y conciertos, aunque podemos concluir que "tuvo una existencia un tanto fantasmal y poco efectiva" ${ }^{60}$. Con gran ironía Eduardo López Chavarri comentó esta fiebre wagneriana, en un gracioso artículo titulado "Manual del wagnerista de ocasión”, en el que ofrecía dieciséis puntos necesarios para el comportamiento de cualquier interesado en manifestar su wagnerismo, a la manera de los ritos iniciáticos para el ingreso en una secta ${ }^{61}$.

En este contexto tan fuertemente wagneriano realiza Conrado del Campo su siguiente trabajo operístico: La tragedia del beso, drama lírico en un acto basado en un episodio de El Infierno de La

55 MuÑoz, Eduardo: “El oro del Rhin”, en El Imparcial, Madrid, 03.03.1910.

56 Borrell, Félix: El wagnerismo en Madrid. Madrid, Imprenta Ducazcal, p. 36.

57 Borrell, Félix: El wagnerismo en Madrid..., p. 35.

58 MuÑoz, Eduardo: “Tristán e Iseo”, en El Imparcial, Madrid, 06.02.1911.

59 "Teatro Real: "La última de Tristán e Iseo", en La Época, 03.03.1911.

60 Turina Gómez, Joaquín: Historia del Teatro Real..., p. 215.

61 López-Chavarri, Eduardo: "Manual del wagnerista de ocasión”, en Revista musical, Bilbao, año II, no 15 (marzo 1910), pp. 60-62. El primer punto era: "Lo primero que has de hacer ioh sencillo aspirante a wagnerista! es aprender de memoria unos cuantos nombres que meterás por doquier cuando se hable de música, aun cuando no sepas bien a las claras lo que significan. Estos nombres son ¡fíjate bien!: capellmeister, leitmotive y festpiel. Ellos son el comienzo, el abecedario del wagneriano: sin saberlos nunca podrás pasar por iniciado." 
Divina Comedia. En realidad la idea de una composición sobre la famosa obra de Dante le había llevado a componer dos fragmentos sinfónicos, estrenados con éxito entre 1908 y 1910 por la Orquesta Sinfónica de Madrid: un prólogo instrumental que representa el encuentro de Dante y Virgilio y un poema sinfónico que describe los horrores del infierno y termina con el retorno de los poetas a la calma de la Naturaleza. Según el programa de estos conciertos, estas dos partes sinfónicas eran el comienzo y el final de un amplio poema musical para coros y orquesta sobre el Infierno de Dante. Sin embargo, esta idea inicial fue transformada en ópera, debido al descubrimiento de un "poema dramático en tres cantos" sobre el infierno de Dante, titulado La tragedia del beso de Carlos Fernández Shaw, que se estrenó en el Teatro de la Princesa de Madrid en marzo de 1910 protagonizado por la gran actriz María Guerrero. Una vez estrenado El final del Don Álvaro, Conrado del Campo emprendió el trabajo de su siguiente ópera durante el verano de 1911, concluyendo la partitura de La tragedia del beso en noviembre de ese mismo año $0^{62}$.

Para el libreto, trabajó directamente sobre el texto estrenado por su amigo y colaborador Carlos Fernández Shaw. En el legado del compositor se ha conservado una edición de este drama con algunas correcciones y anotaciones musicales del propio Conrado del Campo, lo que nos muestra su fidelidad al poema dramático original, del que mantuvo los mismos versos cortando algunas escenas secundarias. El único añadido fue la aparición de un pastor al inicio del segundo cuadro, un acertadísimo efecto escénico que servía -según señala Adolfo Salazar- "para preparar de una manera delicada y bellísima la transición del ambiente trágico del cuadro primero a la gozosa escena siguiente"63. Seguramente estos cambios se realizaron bajo la supervisión del propio Fernández Shaw, su amigo y colaborador, aunque la grave enfermedad del poeta -que fallecería en junio de 1911- obligó al propio Conrado del Campo a colocar en su ópera algunos versos propios.

La tragedia del beso se basa en el famoso episodio de Paolo y Francesca de la Divina Comedia de Dante, los amantes que penan condenados por su trágico amor adúltero y que encuentran los poetas en su viaje por los círculos del infierno. El asunto inspiró varias obras líricas de esta época como la verista Francesca da Rimini de Riccardo Zandonai (1914), Francesca da Rimini de Serguei Rachmaninov ${ }^{64}$ (1906) y Paolo e Francesca de Luigi Mancinelli (1907) ${ }^{65}$, estas dos últimas compuestas también bajo una fuerte influencia wagneriana. Curiosamente Enrique Granados trabajó en este mismo tema por

62 Conservada en el Fondo "Teatro Lírico" de la Sociedad General de Autores (Referencia: MPo/310).

63 Salazar, Adolfo: "La Tragedia del Beso", en Arte musical, junio 1915.

64 Francesca da Rimini de Rachmaninov (sobre libreto de Modest Chaikovski, estrenada en el Teatro Bolshoi de Moscú) recreaba además del episodio de los amantes el viaje de los poetas por el infierno, en un episodio sinfónico que fue criticado por su estatismo y escaso dramatismo. Martyn, Barrie: Rachmaninoff. Composer, Pianist, Conductor. Aldershot, Scholar Press, 1990, pp. $160-168$.

65 Luigi Mancinelli (*1848; †1921) fue conocido en su época sobre todo como director de orquesta con una amplia carrera internacional, siendo uno de los principales impulsores del wagnerismo tanto en Italia como en España, dirigiendo en el Teatro Real de Madrid los estrenos de Tannhäuser (1890) y Los maestros cantores (1893). Significativamente, el estreno de Paolo e Francesca (11 de noviembre de 1907) en el Teatro Comunale de Bologna, estuvo precedido de quince funciones de Tristán (en la versión en italiano, habitual en aquella época) dirigidas por el propio Mancinelli; en el Teatro Real de Madrid se vio en febrero de 1915, siendo recibida con gran frialdad. Mariani, Antonio: Luigi Mancinelli. La vita. Lucca, Akademos, 1998, pp. 74-75, 229, y $254-255$. 
estos años en su poema sinfónico Dante op. 21, cuyas dos partes describían la entrada al infierno y el episodio de Paolo y Francesca, este último cantado por una contralto directamente sobre los versos italianos originales de Dante ${ }^{66}$. La tragedia del beso de Conrado del Campo se desarrollaba en un acto único en tres cuadros: el primero presenta a Dante y Virgilio llegando al infierno donde encuentran entre lamentos de los condenados a Paolo y Francesca; después un súbito cambio de decorado nos llevaba a la corte medieval italiana para ver su trágica historia de amor en la que fueron sorprendidos por Lanciotto Malatesta, muriendo atravesados por una espada que les condenaba a estar siempre unidos; finalmente un breve cuadro final nos devuelve al infierno donde vemos cómo los dos poetas se alejan mientras a lo lejos se escucha la voz de un pastor.

El paralelismo de la historia con el Tristán wagneriano resultaba bastante evidente, y puede ser la causa de la atracción que tuvo este tema no sólo en Conrado del Campo sino en los otros compositores mencionados. Al fin y al cabo el episodio recreado por Dante tenía también su base en las leyendas artúricas e incluso en el mismo canto v del Infierno -donde se describe el segundo círculo en el que están los que penan por lujuria- está condenado el propio Tristán. Además, el planteamiento escénico resultaba similar al ideado por Wagner, teniendo su episodio central en la declaración de amor a través de un largo e intenso dúo de la pareja protagonista que es interrumpido bruscamente por la aparición del marido engañado, que precipita el desenlace y la destrucción. Así, el tema central se mueve en los mismos ejes temáticos wagnerianos: el amor como fuerza irrefrenable y a su vez como fuerza destructora. La similitud tristanesca era llevada en La tragedia del beso hasta el nivel del detalle, incluyendo al comienzo del segundo cuadro una canción de un pastorcillo precedida de un solo del saxofón contralto (Ejemplo 3), un episodio que recordaba inevitablemente al del pastor en el desesperanzado inicio del tercer acto del Tristán wagneriano con su triste solo en el corno inglés.

\section{EJEMPLO 3}

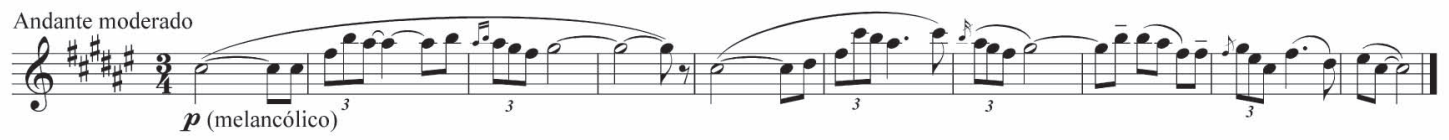

Algunos críticos censuraron un detalle tan evidente, aunque Adolfo Salazar -comprendiendo los valores musicales de la nueva ópera de Conrado del Campo, que calificó como "una verdadera obra maestra"- defendió su originalidad, censurando con ironía la obsesión de los críticos por buscar influencias en todos los estrenos españoles:

66 El estreno de la segunda parte se realizó en el Palau de la Música Catalana a finales de febrero de 1910, bajo la dirección del muniqués Franz Beidler con la contralto Dachs. La crítica también destacó su wagnerismo: "Está concebido con grandiosidad y admirablemente desarrollado, no exento de originalidad a pesar de ciertas reminiscencias wagnerianas." GIBERT, V. M. de: "Barcelona”, en Revista musical, Bilbao, año II, nº 15 (marzo 1910), p. 63. 
"Hasta tal punto llegan a afinar la puntería esos "cazadores de reminiscencias", bautizados así graciosamente por Weingartner, y hasta tal grado de obsesión llegan los amantes de descubrir parentescos, que hoy en día es imposible hacer oír una frase en la tuba sin que se exclame inmediatamente: 'Wagner', o emplear un pedal de contrafagot sin gritar 'Strauss', ni sentar dos amantes en un banco sin que se piense en Tristán, ni hacer sonar un caramillo campestre sin referirse al solo de corno del tercer acto de esa incomparable creación wagneriana. Solo así se concibe que se haya podido comparar musicalmente la canción del pastor de La tragedia del Beso, con ese momento homólogo al de Tristán; sin parar mientes en los significados opuestos de ambas situaciones dramáticas, sin detenerse a pensar que mientras nacía uno de esos casos [Tristán] como flor dolorosa en el ambiente de la melancolía y de tristeza, acentuando con su matiz de desesperanza los trágicos tonos de la obra, en La tragedia del Beso tenía una misión absolutamente distinta: la de disipar el efecto tétrico del prólogo y preparar sin brusquedad la escena posterior" $"$.

A pesar de este comentario, La tragedia del beso se inspiraba de una manera muy directa en el lenguaje musical del Tristán wagneriano. La escritura cromática servía para caracterizar tanto el ambiente desesperanzado del infierno como la intensa pasión amorosa de la pareja protagonista. Además la gran actividad orquestal y polifónica nos remite a las activas texturas wagnerianas. Un buen ejemplo lo encontramos en la llegada de Dante y Virgilio (Ejemplo 4), cuando los dos poetas leen la fatídica inscripción que franquea el infierno (el famoso Lasciate ogni speranza voi che entrate traducido por el poeta español como Dejad los que aquí entréis toda esperanza). El tema inicial -un amplio solo de los violonchelos- se va ralentando progresivamente a manera de recitado, ofreciendo una rica fluctuación cromática. Armónicamente también podemos apreciar una gran actividad, que contribuye a caracterizar la ansiedad con que Virgilio lee la famosa inscripción de entrada al infierno, mediante giros de tercera y enlaces cromáticos. Así desde el claro Sol Mayor inicial, se realiza sin preparación un giro a Mi bemol Mayor con las primeras palabras de Dante, que funciona como dominante de La bemol menor, acorde al que se llega enriqueciendo cromáticamente la textura orquestal y apoyándose en un acorde disminuido; un rápido giro final hace que termine el pasaje inesperadamente en Fa bemol Mayor, produciendo un efecto de cadencia rota. Todos estos recursos armónicos nos remiten a la intensa expresividad del cromatismo wagneriano.

67 Salazar, Adolfo: "La tragedia del Beso", en Arte Musical, Madrid, 21.05.1915. 


\section{EJEMPLO 4}
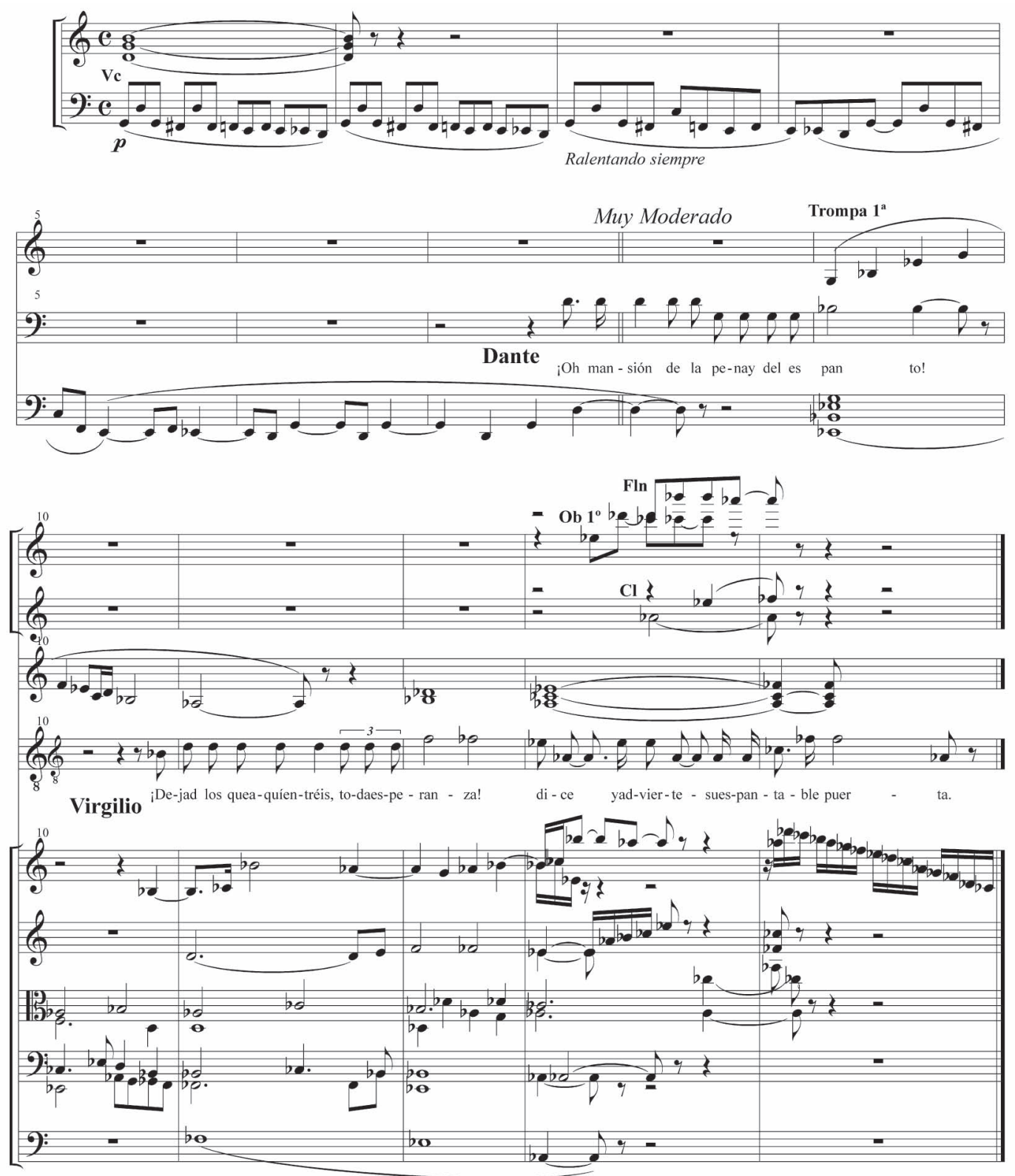

El carácter sinfónico de la partitura resulta evidente en la continua actividad instrumental que acompaña a las voces con un denso tejido de Leitmotiven. En el ejemplo anterior aparecen dos de los más significativos: un lírico arpegio (aquí en la trompa $1^{\text {a }}$ ) que representa la nobleza y majestuosidad de los 
poetas y una tensa apoyatura (en oboes y flautín) adecuada para reflejar las tensiones del infierno. Además en el drama se insertan algunos pasajes puramente orquestales que servían para articular poéticamente la obra, como un anhelante preludio inicial o la transición hacia el segundo cuadro, con el mencionado solo de saxo. De hecho, la música del tercer cuadro incorporaba casi de manera literal gran parte del poema sinfónico, lógicamente con algunos pequeños ajustes para la incorporación de las partes vocales ${ }^{68}$. Se conseguía así un cuadro de carácter sinfónico con gran capacidad evocadora, en el que la orquesta acompaña el alejamiento de Dante y Virgilio de la oscuridad infernal hacia la luz del día, que avanzan según la acotación escénica del propio Del Campo "lenta y noblemente con severa majestad clásica... denotando la emoción que en sus almas domina"; mientras a lo lejos se escucha la voz de un zagalillo y el repique de las campanas que señalan la llegada del alba. El crítico de La Época destacó el interés de estas partes instrumentales, comentando especialmente esta inserción en el contexto del final de la nueva ópera:

"El manejo de la orquesta, es un arte especialísimo de Conrado del Campo, y en la obra actual no sabemos qué admirar más: si su diversidad o su riqueza. Aquel prólogo, digno de Wagner, contrasta profundamente con el delicioso scherzo con que comienza la acción fundamental; el turbulento y trágico desenlace del drama, con la calma y serenidad que le sucede cuando los poetas inmortales ascienden de las profundidades infernales a la augusta paz de la Naturaleza, envuelta aún en las tinieblas de la noche, poco a poco disipadas. Este fragmento final, que ya hemos oído en conciertos sinfónicos, es de una inspiración elevadísima y de una consecución soberbia" ${ }^{\circ 9}$.

El otro fragmento sinfónico -el prólogo instrumental- no se incorporó a la música de La tragedia del beso, a pesar de que describía la misma situación escénica del comienzo con la llegada de Dante y Virgilio al infierno. No obstante, resulta posible interpretarlo a la manera de obertura ya que el final del Tranquilo en Sol Mayor del prólogo sinfónico enlaza perfectamente con el enérgico arranque del Allegro vivace también en Sol del comienzo de la ópera. De hecho, algunas críticas poco claras parecen sugerir que se produjo esta posibilidad en el estreno ${ }^{70}$.

El gusto por las texturas densas y la actividad orquestal y contrapuntística era un rasgo del estilo musical de Conrado del Campo. Ya en una de las primeras cartas a su discípulo Ángel Barrios le realizaba una serie de observaciones, que definían muy bien los intereses musicales del maestro en este sentido:

"Mi buen amigo: aprovechando ratos libres, no muy frecuentes por desgracia, he examinado y corregido los números que me envió. Por la razón citada he tardado tanto. Mañana saldrá para esa los cuatro números. La orquestación suya está bien dispuesta pero peca de excesivamente sobria, tenue, temerosa,

68 Los folios 169 al final (185) de La tragedia del beso reproducen casi exactamente los compases 56-216 del poema sinfónico La Divina Comedia: Infierno. Ver edición de Editorial de Música Española Contemporánea, 2001.

69 Interino: "Real: La tragedia del beso", en La Época, Madrid, 19.05.1915.

70 "De La tragedia del beso conocíamos ya el hermoso prólogo... Al correrse la cortina al terminarse el prólogo, estalló en la sala una formidable salva de aplausos... Se descorrió de nuevo la cortina, y comenzó la acción de la obra propiamente dicha." N. R. de C.: "Teatro Real”, en La Correspondencia de España, 19.05.1915. 
débil. Para el resto, sobre todo, es preciso instrumentar con más robustez, con más cuerpo. Conviene también cuidar más el color buscando efectos de sonoridad, con más decisión, sin timideces. Fíjese en las enmiendas que he hecho, y que tienden a eso. [...] Y no olvide mi consejo, Más resolución, más nervio, más amplitud en el empleo de los elementos orquestales"71.

Este carácter sinfónico de la partitura de La tragedia del beso no debe hacernos olvidar la importancia de lo vocal en la ópera, especialmente en las intensas partes de la pareja protagonista. La soprano que hacía el papel de Francesca, además de su encuentro con los dos poetas en el primer cuadro, debía afrontar un intenso monólogo en el segundo cuadro (folios 101 al 113). El papel fue estrenado por Ofelia Nieto, quien con sólo quince años iniciaba con esta ópera su prometedora carrera en el Teatro Real; la había descubierto el maestro Vives un año antes buscando una protagonista para Maruxa, que encontró en esta destacada alumna de la academia del tenor Simonetti. Rogelio del Villar recordaba años más tarde estas funciones en las que "su voz era algo realmente excepcional, por su calidad, extensión, pureza de timbre y la facilidad y maestría con que la manejaba"72. Aunque rara vez afrontó la Nieto el repertorio wagneriano, sus capacidades vocales le permitían enfrentarse el difícil canto dramático, con su carácter declamatorio y su resistencia vocal en extensión y amplitud. De hecho, algunos críticos censuraron la excesiva dureza de las partes vocales, no sólo la de la soprano sino también la del tenor, cantado por Pascual Roig quien se mostró incapaz de afrontar su papel. Eduardo Muñoz en El Imparcial comentó que “Ofelia Nieto luchó con una tessitura despiadada y con una parte fatigosa... y el tenor Roig, en quien son de estimar los desesperados esfuerzos que realizó para lograr ser oído, aunque en honor a la verdad no pudo conseguirlo completamente" 73 .

El momento culminante de la ópera era el largo dúo de amor de la pareja protagonista (folios 114 al 151), quienes se encuentran clandestinamente en el jardín antes de ser sorprendidos. Las resonancias tristanescas de la situación escénica se realzaban con un lenguaje cromático de gran intensidad vocal e instrumental de fuerte influencia wagneriana. En la partitura son frecuentes indicaciones como apasionado, con vehemencia o enérgico, que reflejan la gran fuerza expresiva que busca Conrado del Campo. Además el lenguaje armónico es bastante dinámico e inestable, con un frecuente apoyo en acordes de séptima disminuida y una activa textura orquestal y contrapuntística (Ejemplo 5). Un crítico describió con acierto esta parte como "dúo en el que hay frases apasionadas, que engalana un trabajo orquestal de maestro" $"$.

71 Carta de Conrado del Campo a Ángel Barrios desde Madrid con fecha 13.12.1912. Legado Ángel Barrios, Archivo del Patronato de La Alhambra y Generalife, Granada. Durante esta década ambos músicos mantuvieron una estrecha relación que se inició como maestro-discípulo, pero que después les llevó a colaborar en varias obras líricas, entre las que destaca la ópera El Avapiés, estrenada en el Teatro Real de Madrid el 18.03.1919.

72 [Del Villar, Rogelio]: "Ofelia Nieto", en Ritmo, nº 33, 01.06.1931.

73 Muñoz, Eduardo: "La tragedia del beso", en El Imparcial, 19.05.1915. Con idéntico sentido irónico hacia el tenor se comentaba en el diario El Liberal del mismo día: "Del tenor Roig hemos de decir que cuando en algunos momentos le oímos, pudimos percibir que dice bien.".

74 C., N. R. de: “Teatro Real”, en La Correspondencia de España, 19.05.1915. 


\section{EJEMPLO 5}
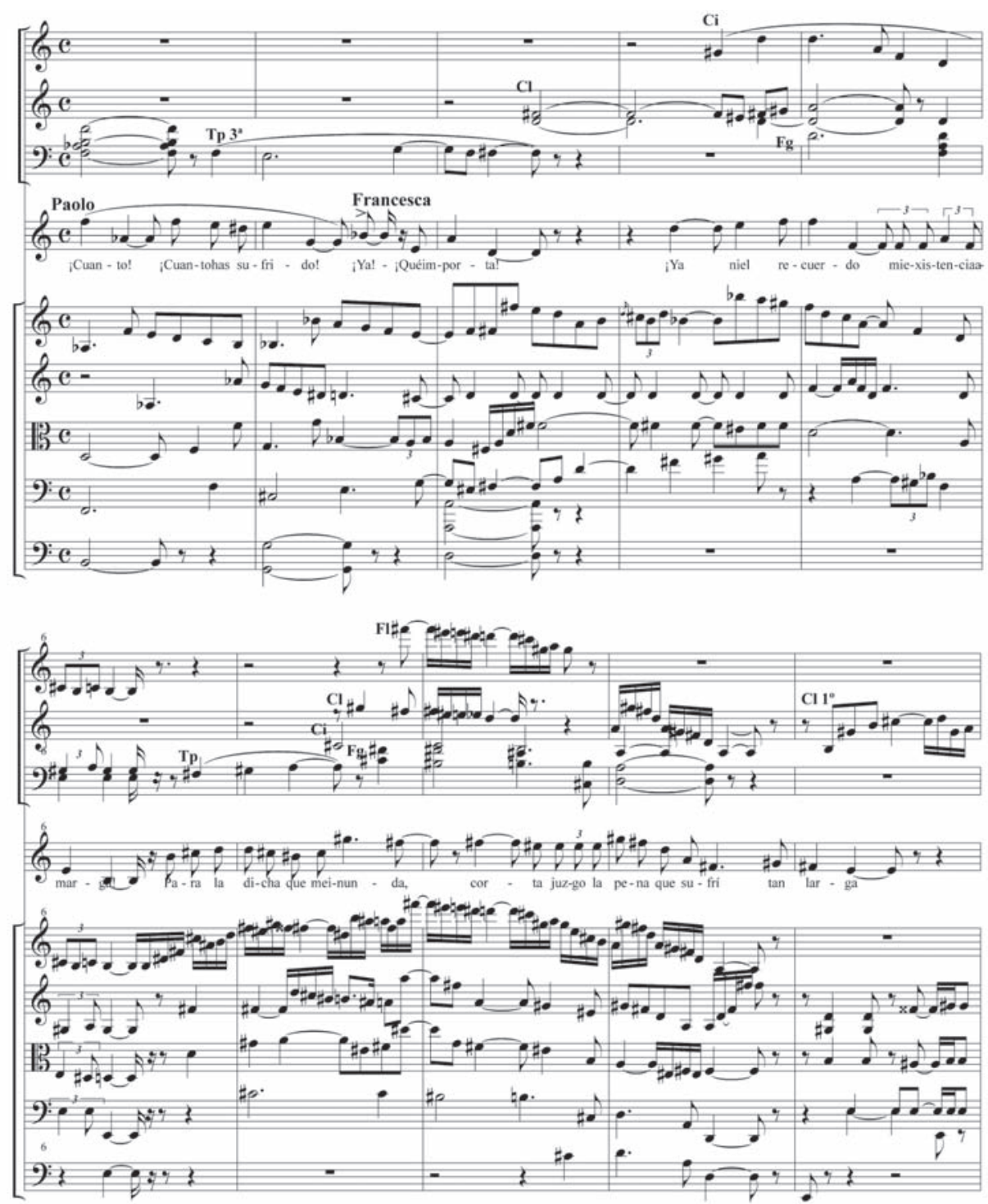

En definitiva, nos encontramos en La tragedia del beso con una de las obras más wagnerianas no sólo de Conrado del Campo, sino de todo el repertorio operístico español. Las resonancias del Tristán son bastante evidentes, tanto a nivel dramático como musical, fruto de la enorme presencia que tiene este título de Wagner en el ambiente musical madrileño de esta época. El público y la crítica reconocieron esta herencia con división de opiniones. Ya hemos visto cómo Adolfo Salazar y Rogelio Villar defendieron la calidad -e incluso originalidad- del nuevo trabajo operístico. Sin embargo, en el diario El Liberal se pudo leer: "Pero Tristán e Iseo no se aparta del pensamiento del espectador mientras oye La tragedia del beso. 
Es una lástima que Conrado del Campo, aún dentro de su manera de ser artista, no haya sabido sustraerse a ese recuerdo"75. Calvo Sotelo en El Debate reconociendo su wagnerismo destacaba la calidad final que "constituía un jalón capital de este noble empeño" en favor de la ópera nacional:

"Patentiza una vez más Conrado del Campo su pericia, más aún, su firmísima sabiduría técnica. La composición es ya para él un arte sin secretos, y aun cuando la armonía se reblandece, deslíe y aún evapora con frecuencia entre el fárrago de notas acumuladas sucesiva y simultáneamente, lo cierto es que jamás falla el maestro, el hombre de ciencia, y que por ello cabe mostrar La tragedia del beso como producción acabada equilibradamente, sin dejadeces ni lapsus que la puedan descomponer.

[...] Y luego, Conrado se aferra con exceso al wagnerismo. Es un wagnerista reconcentrado, casi fanático del coloso germano. Fuera de él rechaza todo horizonte. De Wagner es el cromatismo que repetidas veces asoma en la escena de amor. De Wagner es la inflexible línea interna que permanece inquebrantable, pese a la multiformidad extrínseca del adorno musical"76.

Lo cierto es que a pesar del interés de La tragedia del beso y de los aplausos recibidos en su estreno su repercusión fue bastante escasa. La ópera tardó cuatro años en programarse, siendo estrenada en el Teatro Real de Madrid dentro de la temporada de primavera de 1915. Unas funciones fuera de la temporada principal dedicadas especialmente a la ópera española, en las que se repuso Margarita la tornera, La Dolores y Maruxa de Vives, la obra de mayor éxito estrenada un año atrás en el Teatro de la Zarzuela. De hecho, gran parte del público no eran los abonados del resto del año y los precios eran bastante más reducidos. Además los cantantes eran en su mayoría jóvenes e inexpertos, con la excepcionalidad del precoz caso de Ofelia Nieto. La tragedia del beso fue el único estreno, del que se ofrecieron sólo tres funciones, en un cartel que se completó curiosamente con una versión castellana de Bastián y Bastiana de Mozart ${ }^{77}$.

La nueva ópera de Conrado del Campo se estrenaba así por compromiso, debido al prestigio alcanzado por su autor, ya que estaba terminada cuatro años antes y se podía haber programado con mayor premura. La dirección corrió a cargo de Arturo Saco del Valle, mientras el propio Conrado del Campo se mantuvo en su atril de las violas, subiendo al final de la representación a recoger los calurosos aplausos. La tragedia del beso se olvidó pronto y su partitura permaneció manuscrita en el archivo de su creador. De esta manera $-\mathrm{y}$ una vez más- el camino de la ópera española no se frenaba por los esfuerzos de los compositores sino por el total desinterés del ambiente musical hacia la producción nacional. Un poco gratificante camino que no desanimó a un Conrado del Campo que continuó componiendo óperas hasta el final de su carrera.

Recibido: 13/09/2006

Aceptado: 07/06/2009

75 Tristán: "Teatro Real”, en El Liberal, 19.05.1915.

76 Calvo Sotelo: "Los estrenos de anoche", en El Debate, 19.05.1915.

77 El crítico del diario $A B C$ (19.05.1915) definió acertadamente la visión de los asistentes del Teatro Real a esta ópera de Mozart: "El público sabía que iba a admirar una monada, un bijou, una miniatura, a la que la antigüedad presta más valor, por lo mismo que al través de ella ha conservado su lozanía y la gracia de su concepción, y acudió solícito y oyó con verdadera devoción Sebastián y Sebastiana, esa deliciosa plática de familia en la que tres únicos personajes se lo cantan y se lo recitan todo.". 